\title{
Comparison of high and low intensity training in well controlled rheumatoid arthritis. Results of a randomised clinical trial
}

Cornelia H M van den Ende, Johanna M W Hazes, Saskia le Cessie, Wim J Mulder, Diane G Belfor, Ferdinand C Breedveld, Ben A C Dijkmans
University Hospital Leiden, Leiden, The Netherlands: Department of Rheumatology C H M van den Ende $\mathrm{J} M \mathrm{~W}$ Hazes

D G Belfor

F C Breedveld

B A C Dijkmans

\section{Department of} Medical Statistics $\mathrm{S}$ le Cessie

\section{Department of Physical Therapy} W J Mulder

Correspondence to: C H M van den Ende, University Hospital Leiden, Department of

Department of Rheumatology, Building 1 C4-R Postbox 9600, 2300 RC Leiden, The Netherlands.

Accepted for publication 21 June 1996

\begin{abstract}
Objective-To investigate the benefit of intensive dynamic exercises in comparison to range of motion (ROM) and isometric exercises in rheumatoid arthritis.

Methods-100 consecutive rheumatoid arthritis patients on stable medication were randomly assigned to (1) intensive dynamic group exercises which included full weight bearing exercises and conditioning exercises on a stationary bicycle while the heart rate was maintained at 70$85 \%$ of the age predicted maximum heart rate, (2) range of motion ( $R O M$ ) exercises and isometric exercises in a group, (3) individual isometric and ROM exercises, and (4) home instructions for isometric and ROM exercises. Variables of physical condition, muscle strength, joint mobility, daily functioning (HAQ), and disease activity were assessed before and after the 12 week exercise course, and 12 weeks thereafter. An intention to treat analysis was performed.
\end{abstract}

Results-Increases in aerobic capacity (n $=77$ ), muscle strength, and joint mobility in the high intensity exercise programme were respectively $17 \%, 17 \%$, and $16 \%$ and differed significantly from the changes in aerobic capacity, muscle strength, and joint mobility in the other exercise groups. No deterioration of disease activity was observed. Twelve weeks after discontinuation of the exercise course the gain in physical capacity had disappeared.

Conclusions-Intensive dynamic training is more effective in increasing aerobic capacity, joint mobility, and muscle strength than ROM exercises and isometric training in rheumatoid arthritis patients with well controlled disease.

(Ann Rheum Dis 1996;55:798-805)

In rheumatoid arthritis pain and inflamed joints lead to a diminished level of physical activity. Apart from the damaging consequences of the disease on joints and muscles, physical inactivity contributes to contractures, muscle atrophy, and poor physical fitness. ${ }^{1-6}$ Rheumatoid arthritis patients are therefore encouraged to exercise in order to improve muscle strength and joint mobility. Traditionally non-weight-bearing, isometric muscle strengthening exercises and range of motion (ROM) exercises have been advocated. Intensive dynamic and weight bearing exercises to improve physical condition were considered inappropriate because of fear of joint damage and deterioration of disease activity. ${ }^{7-9}$

Recent research suggests the efficacy of dynamic weight bearing exercises in improving muscle strength and physical condition. However, many of the clinical trials that have been done have not had a randomised design or only involved a small number of patients. ${ }^{10-20}$

The aim of this study was to investigate whether dynamic weight bearing exercises have a more beneficial effect on physical functioning than isometric non-weight-bearing exercises in rheumatoid arthritis patients.

\section{Methods}

STUDY DESIGN

The study was a randomised controlled trial consisting of four different exercise programmes, all lasting for 12 weeks: (1) high intensity exercise programme in a group; (2) low intensity exercise programme in a group; (3) low intensity exercises individually supervised; and (4) written instructions for home exercises. Since conditioning exercises (high intensity exercises) require special facilities this form is mostly provided as a group activity. Group exercises give the opportunity for socialisation and are likely to have a positive impact on feelings of wellbeing and functional capacity. On the other hand it is more usual for clinicians to prescribe for their rheumatoid arthritis patients exercises individually supervised by their own physical therapist. In order to exclude the influence of the "group" factor, low intensity exercises were incorporated in the study design in two forms, namely as individual exercises and as group exercise. A group of patients with written instructions for home exercises served as a control group. 
STUDY POPULATION

One hundred consecutive patients were recruited from the outpatient rheumatology clinic of the University Hospital of Leiden, fulfilling the following inclusion criteria: (1) rheumatoid arthritis according to the 1987 ACR criteria $^{21}$; (2) aged between 20 and 70 years; (3) on stable medication for the last three months; (4) able to cycle on a home trainer. Exclusion criteria were: (1) high disease activity, such that changing or starting a slow acting antirheumatic drug was considered necessary by the rheumatologist; (2) inability to tolerate physical fitness training due to presence of serious cardiac or lung disease; and (3) presence of one or more arthroplasties of weight bearing joints. After informed consent 100 rheumatoid arthritis patients were randomly assigned to one of the four different exercise programmes. The study was approved by the medical ethics committee of the hospital.

\section{EXERCISE PROGRAMMES}

High intensity exercise programme

Twenty five patients were allocated to four exercise classes. All classes met for one hour, three times a week. The training included a warm up, an interval programme of 12 exercises following a standardised protocol, bicycle exercise for 20 minutes, and cooling down exercises. The interval exercise programme consisted of dynamic weight bearing exercises like knee bending, step ups, and walking at fast speed, alternating with muscle strengthening exercises for the trunk and the upper extremities. Exercises were performed at high pace. Every four weeks a new interval exercise programme with higher exercise load was offered. During cycling, heart rate was maintained at $70-85 \%$ of the age predicted maximum heart rate. Patients were educated in handling pain. In case of extra pain lasting for more than two hours, and occurring within 24 hours after an exercise session, the exercise load was temporarily decreased.

\section{Low intensity group exercise programme}

Twenty five patients were divided into four classes. These classes met for one hour, twice a week. The exercise programme consisted of range of motion exercises and non-weightbearing isometric, muscle strengthening exercises of the trunk and upper and lower extremities at a low pace, and no resistance was applied. Exercises were performed in prone, sitting, and standing positions.

Low intensity individual exercise programme Twenty five patients had individual exercise therapy, twice a week. The programme consisted of the same exercises as described for the low intensity group exercise programme. The patients were free to choose their own physical therapist who was instructed by the investigator.

\section{Home exercise programme}

Twenty five patients were given written instructions for range of motion and isometric exercises and were advised to exercise at least twice a week for 15 minutes. No further attempt was made during the intervention period to motivate these patients to exercise.

\section{ASSESSMENTS}

All assessments were done by a single observer who was not blinded to treatment group. However, all test procedures were standardised and test indices included subjective as well as objective measurements. Assessments were done at baseline, after the exercise period of 12 weeks, and after another 12 weeks.

\section{Physical condition}

Aerobic capacity $\left(\dot{\mathrm{V}}<\mathrm{V}>\mathrm{O}_{2}\right.$ max in $\mathrm{ml} \mathrm{kg}^{-1}$ $\mathrm{min}^{-1}$ ) indirectly estimated according to Astrand $^{22}$ was used as the indicator of physical condition. The submaximal bicycle ergometer tests followed a standard graded protocol ${ }^{23}$ and all tests were performed on the same calibrated electromechanically braked ergometer (Lode, The Netherlands).

\section{Muscle strength}

Knee extensor and flexor strength was measured by an isokinetic dynamometer (Enknee, Enraf Nonius, Delft, The Netherlands). The patients were seated with hips flexed at $90^{\circ}$, strapped to the seat and the back of the chair. The lever of the dynamometer was attached to the lower leg just above the ankle joint. Test positions were recorded and the same test positions were used for all subsequent measurements. Each subject was tested in the same order, beginning with isokinetic strength at $120^{\circ} \mathrm{s}^{-1}$ and $60^{\circ} \mathrm{s}^{-1}$ angle velocity and followed by isometric strength at a fixed position of $45^{\circ}$ flexion of the knee joint. Before testing, patients were made familiar with the dynamometer and the test procedures and were allowed a try out before the actual testing took place. During testing the patients were given standardised instructions.

The peak torque of four attempts of isokinetic strength at $120^{\circ} \mathrm{s}^{-1}$ and $60^{\circ} \mathrm{s}^{-1}$ angle velocity and the peak torque of three attempts of isometric contractions were used as indicators of muscle strength.

\section{foint mobility}

Range of motion was assessed by using the EPM-ROM score, a measure for joint mobility derived from 10 selected joint motions of a number of smaller and larger joints. ${ }^{24}{ }^{25}$ Joint motions included in the EPM-ROM are: elbow flexion and elbow extension, palmar and dorsal flexion of the wrist, the average flexion of the metacarpal joints, abduction thumb, flexion proximal interphalangeal joint of the thumb, hip flexion, knee extension, and ankle plantar flexion. Joint motions were recorded in degrees. Furthermore, according to the EPM-ROM scale each joint motion was rated on a four point scale.

\section{Functional ability}

At each assessment patients were asked to complete the health assessment questionnaire (HAQ), ${ }^{26}$ which is validated for Dutch rheumatoid arthritis patients, ${ }^{27}$ and the 
subscales of the Dutch arthritis impact measurements scales (Dutch-AIMS) concerning pain, anxiety and depression. ${ }^{28}$ Observed functional ability was measured by means of the walk test (time needed to walk a distance of 50 feet) and the stair test (time needed to go up and down a flight of 10 steps).

\section{Disease activity}

Disease activity was assessed by the following variables: number of swollen joints (maximum range 0-20), a modified Ritchie articular index (maximum range 0-69), Westergren erythrocyte sedimentation rate (ESR), $\mathrm{C}$ reactive protein, platelet count, and the patient's score on a visual analogue scale (VAS) for pain, morning stiffness, tiredness, and disease activity (0-10 $\mathrm{cm})$. The study did not interfere with the routine drug treatment. Any changes in medication were recorded at each assessment.

\section{STATISTICAL ANALYSIS}

For each variable, change scores were calculated by subtracting baseline scores from evaluation scores. A sample size of 22 patients per exercise regimen was required to detect a $20 \%$ improvement in physical condition $\left(\mathrm{VO}_{2} \mathrm{max}\right)$ between the high intensity and low intensity exercise groups with a significance level of 0.05 and a power of $90 \%$, assuming the mean $\mathrm{VO}_{2} \max$ at baseline to be $20 \mathrm{ml} \mathrm{kg}^{-1}$ $\mathrm{min}^{-1}$ and the standard deviation of the change scores to be $4 \mathrm{ml} \mathrm{kg}^{-1} \mathrm{~min}^{-1}$. Sample sizes were set at 25 patients per group allowing for possible drop outs.

For each of the 12 muscle strength measurements the percentage change was calculated in relation to baseline values. The average percentage change of the 12 measurements was used as the indicator of the overall change in muscle strength of the extensors and flexors of both knees.

To evaluate the effect of the exercise programmes an intention to treat analysis was performed. After the exercise course (at 12 weeks) and at 24 weeks, data were available from 99 and 93 patients respectively. All patients, including the patients who prematurely left the exercise course, were invited to come to the evaluations at 12 and 24 weeks. One rheumatoid arthritis patient in the low intensity group exercise programme left the programme after the first two weeks and refused to come to the further assessments. Seven patients (one in the high intensity exercise programme, three in the low intensity group exercise programme, two in the low intensity individual exercise programme) were not available at the 24 weeks assessment because of surgery $(n=1)$, traffic accident $(n=$ $1)$, pregnancy $(n=1)$, non-compliance $(n=2)$, emigration $(n=1)$, and personal reasons $(n=$ 1). Between group differences at baseline were investigated by $\chi^{2}$ or one way analysis of variance where appropriate. Between group differences in change scores after the training period and the follow up period were examined by one way analysis of variance. Multiple comparisons between mean change scores were made according to Tukey. ${ }^{29}$

\section{Results}

Over a period of one year (January 1993 to January 1994) 260 consecutive patients were eligible for the study. A total of 160 rheumatoid arthritis patients did not enter the study because they were not able or willing to participate in an exercise class three times a week. The most frequent arguments for declining to enter the study were reasons related to working hours, lack of time or motivation, and difficulties in transport to the hospital. The 160 non-participating patients did not differ significantly from the participating patients in sex ratio and age (data not shown).

The basic characteristics of the patients of the four exercise programmes are listed in table 1. Sixty three female and 37 male patients with a mean age of 52 years and a mean disease duration of about 10 years participated in the study. The characteristics of the patients resemble other populations of studies conducted in rheumatoid arthritis. At baseline there were no significant differences between the groups in demographic and clinical characteristics.

COMPLIANCE WITH THE EXERCISE PROGRAMMES Ten patients did not complete the exercise course-three in the high intensity exercise programme, five in the low intensity group exercise programme, and two in the low intensity individual exercise programme. Five patients-three in the high intensity exercise programme and two in the low intensity group exercise programme-left the exercise therapy prematurely because of an increase in complaints. Other reasons for discontinuing the exercise programme were: the programme was too time consuming $(n=2)$, the study caused too much psychological strain $(n=1)$, and personal reasons not related to the disease $(n=2)$. There were no significant differences at baseline in any of the assessed variables between the completers and the noncompleters (data not shown). The average attendance rate for all three supervised exercise programmes was $75 \%$, including the non-completers. Data on the mean changes in

Table 1 Demographic and clinical characteristics at baseline of 100 patients with rheumatoid arthritis randomly assigned to four different exercise programmes. Values are means (SD) unless otherwise stated

\begin{tabular}{|c|c|c|c|c|}
\hline & $\begin{array}{l}\text { High } \\
\text { intensity } \\
\text { group } \\
(n=25)\end{array}$ & $\begin{array}{l}\text { Low } \\
\text { intensity } \\
\text { group } \\
(n=25)\end{array}$ & $\begin{array}{l}\text { Low } \\
\text { intensity } \\
\text { individual } \\
(n=25)\end{array}$ & $\begin{array}{l}\text { Home } \\
\text { exercise } \\
\text { individual } \\
(n=25)\end{array}$ \\
\hline Age, years & $\begin{array}{l}51.1 \\
(9.5)\end{array}$ & $\begin{array}{l}47.7 \\
(13.6)\end{array}$ & $\begin{array}{l}53.1 \\
(12.1)\end{array}$ & $\begin{array}{l}56.1 \\
(10.9)\end{array}$ \\
\hline Sex, F/M & $13 / 12$ & $16 / 9$ & $16 / 9$ & $18 / 7$ \\
\hline $\begin{array}{l}\text { Disease duration, } \\
\text { years }\end{array}$ & $\begin{array}{l}11.5 \\
(8.4)\end{array}$ & $\begin{array}{l}8.4 \\
(5.8)\end{array}$ & $\begin{array}{l}8.6 \\
(7.1)\end{array}$ & $\begin{array}{l}11.2 \\
(9.8)\end{array}$ \\
\hline $\begin{array}{l}\text { Rheumatoid factor } \\
\text { seropositivity, } \\
\text { yes/no }\end{array}$ & $21 / 4$ & $20 / 5$ & $19 / 6$ & $19 / 6$ \\
\hline $\begin{array}{l}\text { Erosive, } \\
\text { yes/no/missing }\end{array}$ & $23 / 2 / 0$ & $20 / 4 / 1$ & $17 / 6 / 2$ & $22 / 2 / 1$ \\
\hline Swollen joint count & $5.2(3.2)$ & $3.0(2.2)$ & $4.4(3.0)$ & $3.6(3.3)$ \\
\hline Ritchie index & $\begin{array}{l}12.0 \\
(7.9)\end{array}$ & $\begin{array}{l}10.4 \\
(7.2)\end{array}$ & $\begin{array}{l}12.5 \\
(7.1)\end{array}$ & $\begin{array}{l}12.4 \\
(7.2)\end{array}$ \\
\hline HAQ & $\begin{array}{l}0.83 \\
(0.61)\end{array}$ & $\begin{array}{l}0.72 \\
(0.53)\end{array}$ & $\begin{array}{l}0.83 \\
(0.65)\end{array}$ & $\begin{array}{l}0.70 \\
(0.61)\end{array}$ \\
\hline $\mathrm{ESR}, \mathrm{mm} \mathrm{h}^{-1}$ & 33 (17) & $28(29)$ & 27 (18) & $31(21)$ \\
\hline
\end{tabular}

HAQ, health assessment questionnaire. 
measures of physical capacity and functional ability are presented in table 2 .

MEASURES OF PHYSICAL CAPACITY

Aerobic capacity

Several patients failed to complete the ergometer test because of poor physical fitness or pain related to rheumatoid arthritis. At baseline 84 patients completed the test. Seven patients (three for reasons related to rheumatoid arthritis, four for reasons not related to rheumatoid arthritis) completed the ergometer test at baseline, but not at 12 weeks. Two patients in the high intensity exercise programme completed the ergometer test after 12 weeks but not at baseline. At 24 weeks an extra three patients did not complete the ergometer test. Hence the change in aerobic capacity could only be analysed in 77 and 74 patients at 12 and 24 weeks respectively. The patients who failed the ergometer test were equally divided over the four exercise programmes with no differences as to the reasons why they failed.

The mean aerobic capacity $\left(\mathrm{VO}_{2} \mathrm{max}\right)$ of the rheumatoid arthritis patients in the high intensity exercise programme improved from 27.6 to $32.2 \mathrm{ml} \mathrm{kg}^{-1} \mathrm{~min}^{-1}(17.0 \%)$. This improvement differed significantly from the minor changes in aerobic capacity of the other exercise programmes.

\section{foint mobility}

The joint mobility as measured by the EPM-ROM scale improved from 10.9 to 9.2 $(15.6 \%)$ in the patients in the high intensity exercise programme. The improvement differed significantly from the changes in joint mobility in the three other exercise programmes. Separate analysis of the joints included in the EPM-ROM scale revealed that the joint flexibility in particular improved in the joints of the lower extremities (table 3 ).

\section{Muscle strength}

The patients in the high intensity exercise programme showed a significant improvement of $16.8 \%$ in the overall muscle strength of the extensors and flexors of the knee. The improvement in muscle strength of the patients of the low intensity individual and group exercise programmes was not significant, at $7.7 \%$ and $7.4 \%$ respectively. The improvement in muscle strength in the high intensity exercise programme was significantly different from the home exercises programme but not from the low intensity exercise programmes.

\section{Measures of functional ability}

There were no significant changes in daily functioning after the exercise period in any of the exercise programmes measured by the HAQ and the Dutch AIMS. None of the exercise groups had significant changes in scores for depression and anxiety (data not shown). Measures of observed functional ability improved significantly over baseline only in the patients in the high intensity exercise programme; the time to perform the walk test decreased from 9.6 to $8.9 \mathrm{~s}(\mathrm{P}=0.03)$, the time to perform the stair test decreased from 10.9 to

Table 2 Mean baseline values and mean changes of variables of physical capacity and functional ability after 12 weeks treatment and at 24 weeks follow up in 100 patients with rheumatoid arthritis randomly assigned to four different exercise programmes

\begin{tabular}{|c|c|c|c|c|c|c|}
\hline \multirow[b]{2}{*}{ Group } & \multicolumn{2}{|c|}{ Baseline } & \multicolumn{2}{|l|}{ After 12 weeks } & \multicolumn{2}{|l|}{ After 24 weeks } \\
\hline & Mean & $(S D)$ & $\begin{array}{l}\text { Mean change from } \\
\text { baseline }\end{array}$ & $95 \% C I$ & $\begin{array}{l}\text { Mean change from } \\
\text { baseline }\end{array}$ & $95 \% C I$ \\
\hline \multicolumn{7}{|c|}{$\overline{\dot{V} O_{2}\left(m l ~ k^{-1} \min ^{-1}\right)}$} \\
\hline HIE & 27.6 & $(7.1)$ & +4.7 & $(2.6$ to 6.8$) \oint^{1}$ & +1.1 & $(-1.6$ to 3.9$)$ \\
\hline LIE-gr & 28.2 & (9.5) & +0.9 & $(-1.2$ to 3.1$)$ & +1.1 & $(-1.2$ to 3.4$)$ \\
\hline LIE-ind & 32.8 & $(9.8)$ & -1.2 & $(-2.8$ to 0.4$)$ & -1.2 & $(-3.4$ to 1.0$)$ \\
\hline $\mathrm{HE}$ & 25.8 & (6.1) & +0.3 & $(-1.6$ to 2.2$)$ & +0.5 & $(-1.6$ to 2.7$)$ \\
\hline \multicolumn{7}{|c|}{ foint mobility (EPM-ROM, $0=$ full flexibility) } \\
\hline HIE & 10.9 & $(2.8)$ & -1.7 & $(-2.5$ to -0.9$) \oint^{1}$ & -0.1 & $(-0.7$ to 0.5$)$ \\
\hline LIE-gr & 8.9 & (3.1) & +0.4 & $(-0.4$ to 1.0$)$ & +0.6 & $(-0.4$ to 1.5$)$ \\
\hline LIE-ind & 9.4 & $(2.5)$ & -0.0 & $(-1.0$ to 0.9$)$ & +0.4 & $(-0.6$ to 1.5$)$ \\
\hline $\mathrm{HE}$ & 8.6 & (2.7) & +0.4 & $(-0.3$ to 1.0$)$ & +0.3 & $(-0.4$ to 1.0$)$ \\
\hline \multicolumn{7}{|c|}{ Mean overall gain in muscle strength (\%) } \\
\hline HIE & & & +16.8 & $(8.4$ to 25.3$) \S^{2}$ & +11.3 & $(3.4$ to 19.3$)\}$ \\
\hline LIE-gr & & & +7.7 & $(0.0$ to 15.4$)$ & +17.0 & $(0.9$ to 33.1$)$ \\
\hline LIE-ind & & & +7.4 & $(-2.3$ to 17.1$)$ & +9.3 & $(-2.2$ to 20.9$)$ \\
\hline $\mathrm{HE}$ & & & -0.9 & $(-6.0$ to 4.3$)$ & -1.9 & $(-5.8$ to 2.0$)$ \\
\hline \multicolumn{7}{|l|}{$H A Q$} \\
\hline HIE & 0.83 & $(0.61)$ & -0.05 & $(-0.19$ to 0.09$)$ & +0.05 & $(-0.11$ to 0.20$)$ \\
\hline LIE-gr & 0.72 & $(0.53)$ & -0.05 & $(-0.20$ to 0.11$)$ & -0.11 & $(-0.30$ to 0.07$)$ \\
\hline LIE-ind & 0.83 & $(0.65)$ & -0.03 & $(-0.13$ to 0.07$)$ & +0.02 & $(-0.20$ to 0.23$)$ \\
\hline $\mathrm{HE}$ & 0.70 & $(0.61)$ & +0.16 & $(0.02$ to 0.29$)$ & +0.10 & $(-0.09$ to 0.28$)$ \\
\hline \multicolumn{7}{|c|}{ Walk test (s) } \\
\hline HIE & 9.6 & (2.3) & -0.7 & $(-1.3$ to -0.1$)$ & -0.8 & $(-1.5$ to -0.1$) \oint$ \\
\hline LIE-gr & 9.9 & (3.4) & -0.4 & $(-1.1$ to 0.4$)$ & -1.1 & $(-2.5$ to 0.2$)$ \\
\hline LIE-ind & 10.2 & $(3.0)$ & +0.0 & $(-0.5$ to 0.5$)$ & +0.1 & $(-1.0$ to 1.2$)$ \\
\hline $\mathrm{HE}$ & 10.0 & $(2.8)$ & +0.1 & $(-0.7$ to 0.5$)$ & -0.1 & $(-0.6$ to 0.5$)$ \\
\hline
\end{tabular}

CI, confidence interval; HIE, high intensity exercise programme; LIE-gr, low intensity group exercise programme; LIE-ind, low intensity indivdual exercise programme; HE, home exercise programme; HAQ, health assessment questionnaire; EPM-ROM scale, Escola Paulista de Medicina range of motion scale.

Significant changes within the group.

${ }^{1} \mathrm{P}<0.001$, high intensity exercise programme significantly different from all three other exercise groups.

${ }^{2} \mathrm{P}=0.02$, high intensity exercise programme significantly different from home exercise programme. 
Table 3 Detailed presentation of changes over baseline in the range of motion (degrees) of the joints included in the EPM-ROM scale after 12 weeks treatment and at 24 weeks follow up in 100 patients with rheumatoid arthritis randomly assigned to four different exercise programmes. Values of left and right extremities were averaged. Values of the three assessed joint motions of the hand are summed

\begin{tabular}{|c|c|c|c|c|c|c|}
\hline \multirow[b]{2}{*}{ Group } & \multicolumn{2}{|c|}{ Baseline } & \multicolumn{2}{|l|}{ After 12 weeks } & \multicolumn{2}{|l|}{ After 24 weeks } \\
\hline & Mean & $(S D)$ & $\begin{array}{l}\text { Mean change from } \\
\text { baseline }\end{array}$ & $95 \% C I$ & $\begin{array}{l}\text { Mean change from } \\
\text { baseline }\end{array}$ & $95 \% C I$ \\
\hline \multicolumn{7}{|c|}{ Elbow flexion and extension } \\
\hline HIE & 127 & $(18)$ & +2 & $(-1$ to 5$)$ & +1 & $(-2$ to 3$)$ \\
\hline LIE-gr & 130 & (15) & +1 & $(-2$ to 3$)$ & -3 & $(-7$ to 2$)$ \\
\hline LIE-ind & 133 & (18) & -2 & $(-5$ to 0$)$ & -3 & $(-7$ to 2$)$ \\
\hline HE & 132 & (13) & -1 & $(-4$ to 1$)$ & 0 & $(-3$ to 3$)$ \\
\hline \multicolumn{7}{|c|}{ Palmar and dorsal flexion wrist } \\
\hline HIE & 80 & $(27)$ & +8 & $(4$ to 12$) s$ & +1 & $(-4$ to 6$)$ \\
\hline LIE-gr & 95 & $(31)$ & -1 & $(-7$ to 4$)$ & -1 & $(-8$ to 6$)$ \\
\hline LIE-ind & 98 & $(22)$ & +2 & $(-5$ to 9$)$ & -4 & $(-10$ to 3$)$ \\
\hline HE & 99 & $(30)$ & 0 & $(-5$ to 4$)$ & -2 & $(-7$ to 4$)$ \\
\hline \multicolumn{7}{|l|}{ Hand } \\
\hline HIE & 159 & $(22)$ & +3 & $(-3$ to 8$)$ & -3 & $(-9$ to 2$)$ \\
\hline LIE-gr & 165 & (22) & -2 & ( -7 to 4$)$ & -4 & $(-10$ to 3$)$ \\
\hline LIE-ind & 163 & $(20)$ & -3 & $(-8$ to 2$)$ & -5 & $(-11$ to 2$)$ \\
\hline $\mathrm{HE}$ & 162 & (16) & -3 & ( -8 to 2$)$ & -1 & $(-6$ to 4$)$ \\
\hline \multicolumn{7}{|c|}{ Hip flexion } \\
\hline HIE & 120 & (6) & +2 & $(1$ to 4$) \S^{1}$ & +2 & $(0$ to 4$)$ \\
\hline LIE-gr & 121 & (8) & -2 & $(-5$ to 0$)$ & -2 & $(-5$ to 0$)$ \\
\hline LIE-ind & 120 & (5) & -1 & $(-3$ to 2$)$ & -1 & ( -5 to 3 ) \\
\hline $\mathrm{HE}$ & 120 & (6) & 0 & ( -2 to 2$)$ & -1 & $(-3$ to 1$)$ \\
\hline \multicolumn{7}{|c|}{ Knee extension ( $0=$ full extension) } \\
\hline HIE & -8 & (7) & +3 & $(1$ to 4$) \S^{2}$ & +1 & $(0 \text { to } 2)^{3}$ \\
\hline LIE-gr & -4 & (5) & -1 & $(-3$ to 0$)$ & -1 & $(-3$ to 0$)$ \\
\hline LIE-ind & -4 & (4) & -1 & ( -2 to 1$)$ & -2 & $(-3$ to 0$)$ \\
\hline HE & -4 & (4) & 0 & $(-1$ to 2$)$ & 0 & $(-1$ to 1$)$ \\
\hline \multicolumn{7}{|c|}{ Plantar flexion of ankle } \\
\hline HIE & 35 & (7) & +3 & $(1$ to 5$) \S^{4}$ & +3 & $(1$ to 5$)$ \\
\hline LIE-gr & 37 & (8) & +2 & $(0$ to 5$)$ & +3 & $(0$ to 5$)$ \\
\hline LIE-ind & 37 & (9) & -2 & $(-4$ to 0$)$ & 0 & (-3 to 2$)$ \\
\hline $\mathrm{HE}$ & 39 & (7) & +1 & $(-1$ to 2$)$ & +2 & (0 to 4 ) \\
\hline
\end{tabular}

CI, confidence interval; HIE, high intensity exercise programme; LIE-gr, low intensity group exercise programme; LIE-ind, low intensity indivdual exercise programme; HE, home exercise programme; EPM-ROM scale, Escola Paulista de Medicina range of motion scale.

Significant changes within the group.

${ }^{1} \mathrm{P}=0.05$, high intensity exercise programme significantly different from low intensity group exercise programme.

${ }^{2} \mathrm{P}<0.001$, high intensity exercise programme significantly different from all three other exercise groups.

${ }^{3} \mathrm{P}=0.01$, high intensity exercise programme significantly different from low intensity individual and group exercise programmes.

${ }^{4} \mathrm{P}<0.01$, high intensity exercise and low intensity exercise group exercise programme significantly different from low intensity

individual exercise programme.

$9.5 \mathrm{~s}(\mathrm{P}=0.01)$, and the mean grip strength increased from 38.5 to $42.8 \mathrm{kPa}(\mathrm{P}=0.03)$. However, there were no significant differences in the change scores between the four groups.

Measures of disease activity

Medication in most of the patients remained unchanged during the exercise period. Three patients in the low intensity group exercise programme and two in the low intensity individual exercise programme started a new second line drug during the exercise period. There were only minor changes in the use or dosage of non-steroidal anti-inflammatory drugs. The number of corticosteroid injections was 2 in the high intensity exercise programme, 0 in the low intensity group exercise programme, 3 in the low intensity individual exercise programme, and 2 in the home exercise programme. In none of the patients who prematurely left the exercise course was the second line drug treatment changed during the 24 weeks of observation.

There were no significant differences in the change scores between the groups after the exercise period in any of the other measures of disease activity except for the number of swollen joints (table 4). The number of swollen joints in the patients in the high intensity exercise programme decreased significantly after exercise. Overall, the disease activity remained unchanged during the exercise period.

RESULTS AT FOLLOW UP (24 WEEKS)

At follow up the significant improvement in aerobic capacity and joint mobility achieved in the patients in the high intensity exercise programme had disappeared (table 2). The patients in the high intensity exercise and the low intensity group exercise programmes still showed a significant improvement in muscle strength compared to the baseline values. The patients in the low intensity group exercise programme gained muscle strength after finishing the exercise course. The improvement in isokinetic flexion $120^{\circ} \mathrm{s}^{-1}$ was significantly different from the changes in muscle strength in the low intensity individual exercise programme (table 5 ).

The significant improvement in 50 foot walking time in the high intensity exercise programme was maintained. There were no differences in the change scores between the groups in any of the measures of functional ability or disease activity. 
Table 4 Mean baseline values and mean changes of variables of disease activity after 12 weeks treatment and at 24 weeks follow up in 100 patients with rheumatoid arthritis randomly assigned to four different exercise programmes

\begin{tabular}{|c|c|c|c|c|c|c|}
\hline \multirow[b]{2}{*}{ Group } & \multicolumn{2}{|c|}{ Baseline } & \multicolumn{2}{|l|}{ After 12 weeks } & \multicolumn{2}{|l|}{ After 24 weeks } \\
\hline & Mean & $(S D)$ & $\begin{array}{l}\text { Mean change from } \\
\text { baseline }\end{array}$ & $95 \% C I$ & $\begin{array}{l}\text { Mean change from } \\
\text { baseline }\end{array}$ & $95 \% C I$ \\
\hline \multicolumn{7}{|c|}{ Swollen joint count } \\
\hline HIE & 5.2 & $(3.2)$ & -1.7 & $(-2.8$ to -7.3$) \oint^{1}$ & -0.9 & (-1.9 to 0.1$)$ \\
\hline LIE-gr & 3.0 & $(2.2)$ & +0.8 & $(0.0$ to 1.6$)$ & +1.0 & $(-0.1$ to 2.0$)$ \\
\hline LIE-ind & 4.4 & $(3.0)$ & 0 & $(-1.1$ to 1.2$)$ & +0.6 & $(-0.8$ to 2.0$)$ \\
\hline $\mathrm{HE}$ & 3.6 & (3.3) & +0.2 & $(-0.7$ to 1.2$)$ & +0.2 & ( -0.9 to 1.3$)$ \\
\hline \multicolumn{7}{|c|}{ Ritchie index } \\
\hline HIE & 12.0 & $(7.9)$ & -0.5 & $(-2.2$ to 1.2$)$ & -0.1 & $(-2.1$ to 1.9$)$ \\
\hline LIE-gr & 10.7 & $(7.2)$ & -0.5 & $(-2.3$ to 1.9$)$ & 0 & ( -2.8 to 2.7$)$ \\
\hline LIE-ind & 12.5 & $(7.1)$ & 0 & $(-1.8$ to 1.8$)$ & +0.3 & $(-2.1$ to 2.6$)$ \\
\hline $\mathrm{HE}$ & 12.4 & $(7.2)$ & +0.2 & $(-1.3$ to 1.7$)$ & +0.1 & $(-1.5$ to 1.8$)$ \\
\hline \multicolumn{7}{|c|}{$\operatorname{Pain}^{a}$ (VAS), cm } \\
\hline HIE & 3.4 & $(2.0)$ & +0.2 & $(-0.5$ to 0.9$)$ & +1.4 & $(0.6$ to 2.1$)$ \\
\hline LIE-gr & 2.2 & $(2.2)$ & +0.2 & $(-0.4$ to 0.7$)$ & +0.1 & $(-0.7$ to 0.9$)$ \\
\hline LIE-ind & 2.4 & $(1.8)$ & 0 & $(-0.6$ to 0.7$)$ & +0.4 & $(-0.4$ to 1.3$)$ \\
\hline $\mathrm{HE}$ & 2.1 & (1.6) & +0.9 & $(0.2$ to 1.5$)$ & +1.2 & $(0.2$ to 2.1$)$ \\
\hline \multicolumn{7}{|c|}{ Global assessment of disease activity ${ }^{b}(V A S), \mathrm{cm}$} \\
\hline HIE & 3.6 & $(2.2)$ & +0.1 & $(-0.8$ to 1.0$)$ & +0.9 & $(-0.6$ to 2.0$)$ \\
\hline LIE-gr & 3.0 & (2.5) & -0.6 & $(-1.5$ to 0.4$)$ & 0 & $(-1.2$ to 1.1$)$ \\
\hline LIE-ind & 3.5 & $(2.8)$ & -0.1 & $(-0.9$ to 0.6$)$ & +0.3 & $(-0.8$ to 1.5$)$ \\
\hline $\mathrm{HE}$ & 2.8 & $(2.3)$ & +0.3 & $(-0.8$ to 1.3$)$ & +0.2 & $(-0.8$ to 1.3$)$ \\
\hline \multicolumn{7}{|c|}{$E S R, m m h^{-1}$} \\
\hline HIE & 33 & $(17)$ & 0 & $(-6$ to 6$)$ & +2 & $(-6$ to 10$)$ \\
\hline LIE-gr & 28 & $(29)$ & -3 & $(-7$ to 2$)$ & -1 & $(-8$ to 5$)$ \\
\hline LIE-ind & 27 & (18) & +3 & $(-3$ to 8$)$ & +7 & $(-2$ to 16$)$ \\
\hline HE & 31 & $(21)$ & -1 & $(-7$ to 5$)$ & -6 & $(-12$ to 0$)$ \\
\hline
\end{tabular}

CI, confidence interval; HIE, high intensity exercise programme; LIE-gr, low intensity group exercise programme; LIE-ind, low intensity indivdual exercise programme; HE, home exercise programme; VAS, visual analogue scale; ESR, erythrocyte sedimentation rate.

$\oint$ Significant changes within the group.

${ }^{1} \mathrm{P}<0.01$, high intensity exercise programme significantly different from low intensity group exercise programme.

' The higher score, the more pain; ${ }^{b}$ the higher score the more disease activity.

\section{Discussion}

The results of our study show that high intensity training improves aerobic capacity, muscle strength, and joint mobility in rheumatoid arthritis patients with well controlled disease. However, most of the gain in physical capacity achieved in 12 weeks of intensive training diminished within the 12 weeks after the exercise treatment had been discontinued. Dynamic weight bearing exercises during a period of 12 weeks did not have a detrimental effect on the activity of the disease.

Our study is one of a limited number conducted on the effect of conditioning exercises in rheumatoid arthritis patients. The results confirm previous findings that such patients can improve physical capacity by vigorous exercises. ${ }^{10-20}$ The exercise programmes of these studies varied in type, intensity, and frequency of exercising. Two randomised studies investigated dynamic full weight bearing exercises twice or more a week, comparable to the present study. ${ }^{1014}$ One of these studies compared walking exercises, aquatics, and ROM exercises. ${ }^{14}$ The other examined the effect of a six week dynamic weight bearing exercise programme in comparison to a static exercise programme. Half the patients exercised at home after being instructed by a physical therapist. ${ }^{10}$ An increase in arthritic symptoms in these studies was not found, but the number of patients was small, ${ }^{14}$ and neither study included the drop outs in the analysis. ${ }^{10}{ }^{14}$ In the present study, subjective, clinical, and blood variables were extensively documented in order to monitor any change in indices of disease activity. The high intensity exercise programme did not cause increased joint symptoms or a rise in an acute phase reactant. The results show that dynamic weight bearing exercises are safe in the short term in rheumatoid arthritis patients with well controlled disease.

The data obtained in this study show the superiority of dynamic weight bearing exercises above the traditionally recommended exercises for rheumatoid arthritis patients. In particular, active ROM exercises appeared to be ineffective in improving joint mobility in well controlled rheumatoid arthritis. It is likely that the functional cyclic exercises of the high intensity exercise programme, like step ups, walking, and cycling, accounted for the improvement in joint mobility of the lower extremities in the patients in the high intensity exercise programme. The efficacy of exercises to improve joint mobility in rheumatoid arthritis is still an under-researched question.

It has been suggested that being involved in a therapeutic exercise experience contributes more to an improvement in physical capacity than the type of the exercise course. ${ }^{14}$ However, the results of our study indicate that the "group factor" had no significant effect on physical capacity and functional ability. The high intensity group exercise programme proved to be more effective than the low intensity group exercise programme, and no differences in effect were found between the low intensity group and low intensity individual exercise programmes. These results indicate that the high intensity exercises resulted in an improvement in physical capacity.

Our study contributes to knowledge about the effects of dynamic exercises in the short term, but little is known about the effect of dynamic weight 
Table 5 Detailed presentation of the changes over baseline in the isokinetic and isometric muscle strength (Nm) of knee extensors and flexors after 12 weeks treatment and at 24 weeks follow up in 100 patients with rheumatoid arthritis randomly assigned to four different exercise programmes. Values of left and right leg are averaged

\begin{tabular}{|c|c|c|c|c|c|c|}
\hline \multirow{2}{*}{ Group } & \multicolumn{2}{|c|}{ Baseline } & \multicolumn{2}{|l|}{ After 12 weeks } & \multicolumn{2}{|l|}{ After 24 weeks } \\
\hline & Mean & $(S D)$ & $\begin{array}{l}\text { Mean change from } \\
\text { baseline }\end{array}$ & $95 \% C I$ & $\begin{array}{l}\text { Mean change from } \\
\text { baseline }\end{array}$ & $95 \% C I$ \\
\hline \multicolumn{7}{|c|}{ Isokinetic extension, $120^{\circ} \mathrm{s}^{-1}$} \\
\hline HIE & 81 & $(35)$ & +11 & $(4$ to 18$) \oint^{1}$ & +6 & $(-1$ to 13$)$ \\
\hline LIE-gr & 86 & $(49)$ & 0 & $(-7$ to 7$)$ & +2 & $(-8$ to 13$)$ \\
\hline LIE-ind & 80 & $(36)$ & -4 & $(-13$ to 6$)$ & -9 & $(-22$ to 5$)$ \\
\hline HE & 78 & (48) & -3 & $(-10$ to 4$)$ & -3 & $(-9$ to 4$)$ \\
\hline \multicolumn{7}{|c|}{ Isokinetic flexion, $120^{\circ} \mathrm{s}^{-1}$} \\
\hline HIE & 67 & (26) & +8 & (2 to 14$) \S$ & +4 & $(-2$ to 10$)$ \\
\hline LIE-gr & 60 & (33) & +6 & (0 to 12$) \oint$ & +8 & $(1$ to 15$) \S^{3}$ \\
\hline LIE-ind & 58 & (29) & 0 & $(-6$ to 5$)$ & -6 & $(-15$ to 4$)$ \\
\hline HE & 58 & $(32)$ & +2 & $(-3$ to 7$)$ & +3 & $(-1$ to 7$)$ \\
\hline \multicolumn{7}{|c|}{ Isokinetic extension, $60^{\circ} \mathrm{s}^{-1}$} \\
\hline HIE & 102 & $(41)$ & +8 & ( -1 to 18$)$ & +5 & $(-3$ to 12$)$ \\
\hline LIE-gr & 109 & (53) & 0 & $(-8$ to 7$)$ & +4 & $(-6$ to 15$)$ \\
\hline LIE-ind & 104 & (42) & 0 & ( -6 to 7$)$ & -12 & $(-23$ to 0$)$ \\
\hline HE & 100 & (51) & -2 & $(-7$ to 4$)$ & 0 & $(-5$ to 5$)$ \\
\hline \multicolumn{7}{|c|}{ Isokinetic flexion, $60^{\circ} \mathrm{s}^{-1}$} \\
\hline HIE & 82 & (31) & +3 & $(-2$ to 9$)$ & +2 & $(-3$ to 7$)$ \\
\hline LIE-gr & 76 & (32) & +3 & $(-1$ to 7$)$ & +4 & $(-1$ to 10$)$ \\
\hline LIE-ind & 73 & (27) & +2 & $(-3$ to 7$)$ & -4 & $(-13$ to 5$)$ \\
\hline HE & 76 & (35) & -1 & $(-4$ to 3$)$ & 0 & $(-4$ to 3$)$ \\
\hline \multicolumn{7}{|c|}{ Isometric extension } \\
\hline HIE & 68 & $(28)$ & +9 & (0 to 19$)$ & +3 & $(-5$ to 10$)$ \\
\hline LIE-gr & 70 & (36) & +4 & $(-3$ to 10$)$ & +11 & (2 to 20) \\
\hline LIE-ind & 65 & (26) & +4 & $(-1$ to 9$)$ & -1 & $(-11$ to 9$)$ \\
\hline HE & 60 & (33) & 0 & $(-4$ to 3$)$ & -2 & $(-6$ to 3$)$ \\
\hline \multicolumn{7}{|c|}{ Isometric flexion } \\
\hline HIE & 71 & (27) & +9 & $(2$ to 16$) \oint^{2}$ & +7 & $(-1$ to 15$)$ \\
\hline LIE-gr & 75 & (37) & -1 & $(-7$ to 5$)$ & +4 & ( -4 to 12 ) \\
\hline LIE-ind & 64 & (25) & +4 & (0 to 8 ) & 0 & $(-8$ to 7$)$ \\
\hline $\mathrm{HE}$ & 71 & (40) & -3 & ( -6 to 1 ) & -1 & $(-5$ to 4$)$ \\
\hline
\end{tabular}

CI, confidence interval; HIE, high intensity exercise programme; LIE-gr, low intensity group exercise programme; LIE-ind, low intensity indivdual exercise programme; HE, home exercise programme; HAQ, health assessment questionnaire; EPM-ROM scale, Escola Paulista de Medicina range of motion scale.

$\int$ Significant changes within the group.

${ }^{1} \mathrm{P}=0.02$, high intensity exercise programme significantly different from individual low intensity and home exercise programme.

${ }^{2} \mathrm{P}=0.01$, high intensity exercise programme significantly different from low intensity group exercise and home exercise programme.

${ }^{3} \mathrm{P}=0.03$, low intensity group exercise programme significantly different from low intensity individual exercise programme.

bearing exercises in the long term. In the few studies on this subject, no damaging effect of exercise therapy has been shown, but these studies included small groups of patients ${ }^{12}$ or were not randomised. ${ }^{11}{ }^{30}$ Rheumatoid arthritis patients may experience long term functional benefit from exercise, but the effect of dynamic exercises on the progression of the disease is unclear. Future research should study the benefit of dynamic training for rheumatoid arthritis patients in the long term.

Our study confirms previous findings that short term intensive exercises can establish an improvement in walking and stair climbing but not in daily functioning as measured by validated self assessment questionnaires. ${ }^{15}{ }^{18} \mathrm{~A}$ possible explanation is that the self assessment questionnaires used are relative insensitive to changes in activities of daily living, ${ }^{31}{ }^{32}$ in particular for this group of rheumatoid arthritis patients with only mild disabling disease, ${ }^{33}$ with respect to the low HAQ score at baseline. Also, it may be that the benefit of exercise therapy will be shown in the long term. In elderly people an association has been found between a long term routine of regular exercise and maintenance of function. ${ }^{34} 35$

The participating patients did not succeed in maintaining fitness after finishing the exercise course. Regular exercise at an appropriate level requires discipline and determination. Many rheumatoid arthritis patients are restricted in their daily functioning by pain and tiredness. Supervision of efficient and attractive exercise therapy might help to embed exercise in daily life and enable the patients to keep up exercising in the long term.

The large number of patients who declined to participate raises the issue of generalisation. Rheumatoid arthritis patients are frequently advised against dynamic weight bearing exercises. The novelty of the study may have contributed to the low participation rate. Moreover, the patients could only enrol in the study if they were able and willing to participate in an exercise programme three times a week at a preset place and fixed time schedules. Since no significant differences in demographic variables between the participating and non-participating patients were found, the results of the study may be considered to be valid for all rheumatoid arthritis patients on stable medication with well controlled disease.

In conclusion, high intensity exercises had more effect on physical condition, joint mobility, and muscle strength than ROM exercises and isometric training in patients with well controlled disease. No detrimental effect of high intensity training on disease activity was found during the exercise course and in the 12 
weeks thereafter. Three months after finishing the exercise programme the gain in physical capacity had decreased. Further research should focus on the benefit and disadvantages of dynamic and weight bearing exercises in the long term.

Supported by the Nationale Commissie Chronisch Zieken foundation and the Health Assurance Company, Zorg en Zekerheid.

1 Hakkinen A, Hannonen P, Hakkinen K. Muscle strength in healthy people and in patients suffering from recent-onset inflammatory arthritis. $\mathrm{Br} \mathcal{F}$ Rheumatol $1995 ; 34: 355-60$.

2 Beals CA, Lampman RM, Banwell RF, Braunstein EM, Albers JW, Castor CW. Measurement of exercise tolerance in patiens with reumatoid arthritis and osteoarthritis. $\mathcal{F}$ Rheumatol 1985;12:458-61.

3 Hsieh LF, Didenko B, Schumacher HR. Isokinetic and isometric testing of knee musculature in patients with rheumatoid arthritis with mild knee involvement. Arch Phys Med Rehabil 1987;68:294.

4 Minor MA, Hewett JE, Webel RR, Dreisinger TE, Kay DR. Exercise tolerance and disease related measures in patients with rheumatoid arthritis and osteoarthritis. $\mathcal{F}$ Rheumatol 1988;15:905-11.

5 Ekblom B, Lovgren O, Alderin M, Fridstrom M, Satterstrom G. Physical performance in patients with theumatoid arthritis. Scand $\mathscr{f}$ Rheumatol 1974;3:121-5.

6 Nordjeso LO, Nordgren B, Wigren A, Kolstad K. Isometric strength and endurance in patients with severe rheumatoid arthritis or osteoarthrosis in the knee joints. Scand 7 Rheumatol 1983;12:152-6.

7 Semble EL, Loeser RF, Wise CM. Therapeutic exercise for rheumatoid arthritis and osteoarthritis. Semin Arthritis Rheum 1990;20:32-40.

8 Rheum 1990;20:32-40.

8 Gerber LH. Rehabilitation of patients with rheumatic diseases. In: Kelley WN, Harris ED, Ruddy S, Sledge CB, eds. Textbook of rheumatology. Philadelphia: W B Saunders, 1994:1904-25.

9 Sutej PG, Hadler NM. Current principles of rehabilitation for patients with rheumatoid arthritis. Clin Orthop 1991;265:116-24.

10 Ekdahl C, Andersson SI, Moritz U, Svensson B. Dynamic versus static training in patients with rheumatoid arthritis. Scand $\mathcal{F}$ Rheumatol 1990;19:17-26.

11 Nordemar R, Ekblom B, Zachrisson L, Lundqvist K. Physical training in rheumatoid arthritis, a controlled long-term cal training in rheumatoid arthritis, a contro

12 Hansen TM, Hansen G, Langgaard AM, Rasmussen JO. Longterm physical training in rheumatoid arthritis. A randomized trial with different training programs and blinded observers. Scand $\mathcal{F}$ Rheumatol 1993;22:107-12.

13 Ekblom B, Lovgren O, Alderin M, Fridstrom M, Satterstrom G. Effect of short-term physical training on patients with rheumatoid arthritis I. Scand $\mathcal{F}$ Rheumatol 1975;4:80-6 .

14 Minor MA, Hewett JE, Webel RR, Anderson SK, Kay DR. Efficacy of physical conditioning exercise in patients with rheumatoid arthritis and osteoarthritis. Arthritis Rheum 1989;32:1396-405.

15 Harkcom TM, Lampman RM, Banwell RF, Castor CW. Therapeutic value of graded aerobic exercise in rheumatoid arthritis. Arthritis Rheum 1985;28:32-9.

16 Kirsteins AE, Dietz F, Hwang SM. Evaluating the safety and potential use of a weight-bearing exercise, Tai-Chi Chuan, for rheumatoid arthritis patients. Am $\mathcal{F}$ Phys Med Rehabil 1991;70:136-41.
17 Lyngberg KK, Danneskiold-Samsoe B, Halskov O. The effect of physical training on patients with rheumatoid arthritis, changes in disease activity, muscle strength and aerobic capacity. Clin Exp Rheumatol 1988;6:253-60.

18 Perlman SG, Connell KJ, Clark A, Robinson MS, Conlon P, Gecht M, Caldron P, Sinacore JM. Dance-based aerobic exercise for rheumatoid arthritis. Arthritis Care Res 1990;3:29-35.

19 Lyngberg KK, Ramsing BU, Nawrocki A, Harreby M, Danneskiold-Samsoe B. Safe and effective isokinetic extension training in rheumatoid arthritis. Arthritis Rheum 1994;37:623-34.

20 Noreau L, Martineau H, Roy L, Belzile M. Effects of a modified dance-based exercise on cardiorespiratory fitness, psychological state and health status of persons with rheumatoid arthritis. Am $¥$ Phys Med Rehabil 1995;74:1927.

21 Arnett FC, Edworthy SM, Bloch DA, McShane DJ, Fries JF, Cooper NS, et al. The American Rheumatism Association 1987 revised criteria for the classification of rheumatoid arthritis. Arthritis Rheum 1988;31:315-23.

22 Astrand PO. A method for prediction of aerobic work capacity for females and males of different ages. Acta Physiol Scand 1960;49:45-60.

23 Vos JA, Binkhorst RA. Fietsergometrie bij de begeleiding van training. Lochem: De Tijdstroom, 1987:19-25.

24 Ferraz MB, Oliveira LM, Araujo PMP, Atra E, Walter SD. The EPM-ROM Scale: an evaluative instrument to be used in rheumatoid arthritis trials. Clin Exp Rheumatol $1990 ; 8: 491-4$

25 Vliet Vlieland TPM, van den Ende CHM, Breedveld FC, Hazes JMW. Evaluation of joint mobility in rheumatoid arthrits trials: the value of the EPM-range of motion scale. f Rheumatol 1993;20:2010-4.

26 Fries JF, Spitz PW, Kraines RG, Holman HR. Measurement of patient outcome in arthritis. Arthritis Rheum 1980; 23:137-45.

27 Siegert CEH, Vleming LJ, Vandenbroucke JP, Cats A. Measurement of disability in Dutch rheumatoid arthritis patients. Clin Rheumatol 1984;3:305-9.

28 Taal E, Jacobs JW, Seydel ER, Wiegman O, Rasker JJ. Evaluation of the Dutch Arthritis Impact Measurement Scales (Dutch-AIMS) in patients with rheumatoid arthritis. $B r f$ Rheumatol 1989;28:487-91.

29 Tukey JW. The problem of multiple comparisons. Princeton NJ: Princeton University, 1953.

30 Stenstrom CH, Lindell B, Swanberg E, Swanberg P, Harms-Ringdahl $\mathbf{K}$, Nordemar $\mathbf{R}$. Intensive dynamic training in water for theumatoid arthritis functional class II-a long-term study of effects. Scand $₹$ Rheumatol II-a long-term

31 Fitzpatrick R, Ziebland S, Jenkinson C, Mowat A. A comparison of the sensitivity to change of several health status instruments in rheumatoid arthrits. $f$ Rheumatol 1993;20:429-36.

32 Liang MH, Larson MG, Cullen KE, Schwartz JA. Comparative measurement efficiency and sensitivity of five health status instruments for arthritis research. Arthritis Rheum 1985;28:542-7.

33 Gardiner PV, Sykes HR, Hassey GA, Walker DJ. An evaluation of the Health Assessment Questionnaire in long-term longitudinal follow-up of disability in rheumatoid arthritis. Br f Rheumatol 1993;32:724-8.

34 Branch LG. Health practices and incident diasability among the elderly. Am $\mathcal{F}$ Public Health 1985;75:1436-9.

35 Mor V, Murphy J, Masterson-Allen S, Willey C, Razmpour A, Jackson ME, et al. Risk of functional decline among well elders. F Clin Epidemiol 1989;42:895-904. 